\title{
Relatos y recursos lingüísticos de la inserción urbana: tres migrantes quechua-hablantes en Lima*
}

\author{
Juan C. Godenzzi ${ }^{1}$ \\ Université de Montréal (Canadá)
}

\section{Resumen}

A partir de los datos proporcionados por tres informantes quechua-hablantes que han migrado a Lima, el presente trabajo analiza tanto sus relatos, que revelan la manera en que toman posición e interactúan en su campo migratorio-urbano, como los recursos lingüísticos con los que elaboran sus discursos, que construyen sus espacios y establecen sus distancias. Se plantea que en su proceso de construcción identitaria, los migrantes utilizan estrategias de hibridación, lo cual les permite recombinar distintas experiencias. En efecto, en el nivel del discurso, el análisis muestra que los migrantes reconfiguran sus identidades a través de la articulación de pertenencias andinas y conurbanas; y en el nivel de las formas lingüísticas, el análisis permite constatar que el castellano de estos tres migrantes andinos bilingües constituye una

\section{Abstract}

From data given by three Quechua-speaking informants who have migrated to Lima, this paper analyses both their stories, which reveal the way they position themselves and interact in their migratory-urban field, and the linguistic resources with which they develop their discourses, construct their spaces, and take their distances. The paper proposes that, in their process of identity construction, the migrants use hybridization strategies, which allow them to recombine their different experiences. In effect, the analysis shows that, discursively, the migrants' Spanish reconfigures their identities through the articulation of their Andean and Urban Cone belonging; and, in terms of language forms, the analysis claims that the Spanish of these three bilingual Andean migrants constitutes an

\footnotetext{
* Stories, Linguistic Resources and Urban Insertion: Three Quechua-speaking Migrants in Lima

Recibido: 25 de mayo de 2017 - Aprobado: 28 de junio de 2017

${ }^{1}$ Doctor en Lingüística por la Universidad de París IV-Sorbonne (Francia). Profesor titular de la Universidad de Montreal. e-mail: juan.carlos.godenzzi@unmontreal.ca
} 
variedad emergente caracterizada tanto por rasgos del castellano andino como por rasgos del castellano de la costa.

Palabras clave: migración, identidades urbanas, cambio lingüístico, dialectos en contacto, español andino. emerging variety characterized by Andean and Costal Spanish features.

Keywords: migration, urban identities, linguistic change, contact dialects, Andean Spanish.

Con una población de 533000 habitantes en 1940 y de 1360,000 en 1957, la ciudad de Lima cuenta actualmente con alrededor de 9 millones de habitantes, la tercera parte de la población peruana, siendo el éxodo rural del interior del país el factor determinante de este crecimiento. Desde una perspectiva histórica, y siguiendo las tres etapas señaladas por Lefebvre (1972) -era agraria, era industrial y era urbana-, cabría distinguir tres modelos de la ciudad de Lima, según el momento: (1) la Lima colonial, la "ciudad letrada", con una topografía continua y delimitada netamente por medio de murallas, en medio de un espacio y una organización agraria; (2) la Lima industrial, en la que se destruyen las murallas, se dilatan los espacios y surgen nuevas élites económicas y culturales, pero en la que se sigue dando la continuidad topográfica, densamente poblada y claramente distinguible frente al campo; (3) la Lima urbana, que se despliega a la vez de modo continuo y discontinuo en un espacio que no presenta límites netos, y en el que se afirman las multicentralidades y la lógica de las redes.

Una de las áreas de esta Lima urbana es el Distrito de Ate, en el cono este de la ciudad. Su población se eleva a los 100000 habitantes y está compuesta tanto por migrantes pobres desplazados por la violencia terrorista durante los años ochenta como por familias provenientes de barrios empobrecidos de la ciudad metropolitana (Proyecto Local, 2006). Es en este distrito en donde habitan los tres migrantes quechua-hablantes, procedentes de la sierra sur, que han sido entrevistados y cuyos testimonios y recursos lingüísticos nos interesa analizar, buscando conocer la manera en que ellos experimentan la ciudad y reconfiguran ahí su identidad cultural y sus rasgos idiomáticos. Se plantea que en el proceso de construcción identitaria de los migrantes se hace especialmente manifiesto el uso de estrategias de hibridación, a través de las cuales se combinan pertenencias, agencias y redes de tradiciones diversas. En lo que se refiere a las lenguas, y para los fines de esta exposición, la estrategia de hibridación significa adoptar una nueva modalidad de habla en 
la que se combinan algunos rasgos del castellano de la sierra sur, tradicionalmente asociado al quechua o al aimara, con algunos rasgos del castellano de la costa o la capital, tradicionalmente no asociado al quechua o al aimara. Al articular mundos culturales distintos, la reconfiguración identitaria de los migrantes andinos no aparece como unitaria ni homogénea, sino más bien como "incompleta" y abierta a la "traducción cultural" (Bhabha, 2002: 150 y 199), haciendo explícita la necesidad de apostar por una nueva cultura y política urbana que haga posible la acción democrática, ya no sólo a la escala de la ciudad tradicional, sino de la conurbación y la metrópolis (Mongin, 2005: 218).

Antes de entrar en materia, debemos precisar algunos conceptos. Por migración suele entenderse el desplazamiento poblacional desde un espacio A hasta un espacio B. Sin dejar de ser válida, esta definición resulta insuficiente y necesita algunas precisiones: (1) No se trata de cualquier desplazamiento, sino de uno que sobrepase cierta escala de espacio, pues no se migra al interior de una misma área geográfica local; y que sea durable, es decir que ocupe buena parte del tiempo de la existencia del individuo. (2) Tal desplazamiento implica un campo migratorio en el cual participan e interactúan diversos actores (los migrantes y todos aquellos que intervienen en la migración), y en el que se confrontan imaginarios, intereses económicos y poderes (Lévy \& Lussault, 2003: 437, 615). (3) El desplazamiento supone, igualmente, un cambio durable de hábitat, es decir de las condiciones materiales, sociales y culturales que expresan un modo de vida y un contexto de pertenencia. (4) El desplazamiento, finalmente, acarrea una modificación profunda de la vida cotidiana y de los actos a través de los cuales el migrante construye su hábitat (437, 615-616).

Por campo urbano se va a entender el espacio relacional y competitivo en el que los actores acumulan un capital urbano, es decir, un "conjunto de bienes materiales e inmateriales producidos e intercambiados que resultan del juego de un estado urbano particular, dotado de una urbanidad específica, en un tiempo $t$ de su historia" (967). La urbanidad es el indicador del estado específico de la organización de los objetos de sociedad en el seno de una situación urbana dada. El nivel de urbanidad depende tanto de la densidad y la diversidad como de la configuración espacial (Lévy \& Lussault 2003: 966; 2007: $301,302,322)$. En la intersección de los campos migratorio y urbano, los migrantes reconstruyen su identidad, entendiendo por tal la toma de posición que se da al interior de un campo social determinado y por medio de la cual uno(s) se confronta(n) a otro(s) en torno a un interés que está en juego, recurriendo para ello a una o algunas de sus pertenencias (étnica, social, cultural, religiosa, nacional, 
regional, urbana, rural, generacional, de género, etc.). Finalmente, por hibridación se va entender, de un modo operativo, la conjunción inusitada de al menos dos elementos heterogéneos, cada uno de ellos asociado a una distinta red de relaciones. Cabe entonces distinguir entre una conexión ya estabilizada entre elementos heterogéneos (que ya no suele considerarse 'hibrida') y una conexión novedosa entre elementos heterogéneos ('híbrida').

En este marco conceptual, nos interesarán, por un lado, los relatos que revelan la manera en que los migrantes toman posición e interactúan en su campo migratorio y urbano (desplazamientos, conflicto de grupos, contrastes entre diversos tipos de hábitat y diversos modos de habitar el espacio); y, por otro lado, los recursos lingüísticos (competencias, usos y formas lingüísticas) con los que los migrantes no sólo elaboran sus discursos, sino que también establecen sus distancias y distinciones, y forjan sus espacios.

\section{El caso de Júver}

Júver G., que tiene 25 años y vive con su mujer y sus dos hijos, trabaja como conductor de combi (microbús que sirve para el transporte público). Nació en un pueblo del Distrito de San Juan Bautista, en la provincia de Huamanga (Ayacucho). Su lengua materna es el quechua y estudió hasta el tercer año de educación secundaria. Tras algunos desplazamientos locales, llegó a Lima a los 12 años. Vive en el asentamiento humano de Huaycán, Distrito de Ate.

\subsection{Relato ${ }^{2}$}

Consideremos el siguiente segmento del intercambio entre la entrevistadora (E) y Júver, el informante (I):

E: ¿Dónde naciste?

I: Yo nací en Huamanga, en Ayacucho, en... por San Juan Bautista que se llama. Después de... tuve un año así, tuvieron problemas mis padres separaron y a mí me re, a mí me llevó mi abuelita al más, a un pueblito más allá de Ayacucho que se llama Pomabamba y ahí radiqué más hasta los doce años. Ahí yo la verdad no sabía, ¿no? sabía hablar el castellano mal, hablábamos

\footnotetext{
${ }^{2}$ Agradezco a Sara Smith y a Luz Helena Rodríguez por sus aportes y sugerencias en el análisis del relato de esta entrevista y de las dos siguientes.
} 
quechua porque hasta ahorita en allá hablan, por eso nomá hablaba el quechua $[\ldots]^{3}$ yo crecí con esa idioma ya prácticamente, señorita, porque en ese ambiente vi, puro eso hablan, nadie hablaba el castellano en allá. El castellano lo hablan en Ayacucho, en la capital mismo, Huamanga mismo, pero en ese pueblo nadie lo hablaba. De ahí me trajieron de allá del pueblo para Ayacucho, para yo aprender el castellano que mi abuelito decía cómo vas a hacer sin... sin saber el castellano vas a hablar por acá te van a insultar.

E: ¿Y cómo era ese lugar donde tú has crecido, los primeros años que tien, de vida?

I: Eh, en el pueblito donde yo viví con mi abuelita, es un sitio hermoso, es uno... un sitio -onde no hay lo que hay acá en Lima, ¿no? todo es, allá es paz, es a la chacra... allá está, nos dedicamos a la chacra, a la agricultura, al... a sembrar maíces.

Júver reconstruye discursivamente su desplazamiento por diversos espacios, desde un espacio fuertemente rural (Pomabamba) hasta otro fuertemente urbano (Lima), pasando por una urbanización intermedia regional (Huamanga). Sugiere también que esos espacios están lingüística y axiológicamente marcados. En efecto, se distinguen lugares predominantemente monolingües en quechua (Pomabamba), lugares bilingües en el que existe un español regional (Huamanga) y lugares predominantemente monolingües en castellano (Lima). El mayor o menor grado de urbanidad guarda correspondencia con la mayor o menor visibilidad del quechua. Y estos espacios, que son a la vez geográficos y sociales, constituyen el ámbito en el que aparecen valoraciones en conflicto: mientras Júver ve su pueblo andino mayormente como un paraíso apacible, aunque afectado por la violencia y el terror, se insinúa otra valoración, incorporada en la sociedad desde el periodo colonial, que minusvalora y discrimina a los pueblos indígenas, sus espacios, su cultura y sus lenguas ("sin saber el castellano... te van a insultar").

\section{E: [...] ¿y cómo surgió la idea de venir acá a Lima, de migrar?}

I: [...] mi -amá tenía miedo de mí, que cualquier rato me lo vayan a llevar esos terroristas, tenía miedo, vámonos

\footnotetext{
${ }^{3}$ Los tres puntos entre corchetes significan un corte hecho por el autor; los tres puntos sin corchetes significa una pausa hecha por el entrevistado.
} 
allá a surgir diciendo. Vinimos con la intención de surgir, salir adelante, trabajar acá a Lima [...]

E: [...] ¿Cómo pensabas que era, este, la ciudad? ¿Cómo pensabas que era Lima?

I: Yo, yo me imaginaba que era bonito, que toda la gente eran así, ¿no? como en allá, que en allá nadie, nadie, te decía así, que tú has habla-o mal, que no hables mal, que dijiste esto que no dijiste esto. [...] Me imaginaba que eran bonitas, casas construidas, eh, los pisos de... de piso, parques, así me imaginaba yo, o sea yo me imaginaba que este era un paraíso, más, más que allá.

E: [...] ¿Cuál era tu, tu mayor, este, esperanza o ilusión?

I: Mi sueño era, señorita, acá...trabajar, sobresalir para tener algo en la vida, ¿no?, pa' mis hermanos.

En el imaginario de Júver, Lima aparecía como un paraíso mayor que el de su pueblo. Y desplazarse hacia Lima significaba para él la posibilidad de surgir ("vinimos con la intención de surgir"). La idea de "surgir" implica acceder a espacios con mayor índice de urbanidad: dejar el "pueblito" de la sierra para tener nuevas oportunidades ("salir adelante") y encontrar un trabajo en la capital. Ahora bien, el espacio imaginado no siempre coincide con la experiencia y Júver comprueba que Lima le resulta un infierno, una cárcel, un lugar de sufrimiento y rivalidad, en donde es "botado" de un lugar para refugiarse en otro, en donde experimenta la burla y el desprecio, particularmente por su manera de hablar el castellano. Así lo refiere en esta secuencia:

E: $\mathrm{Mm}$, eh, el contacto con tus eh, tus nuevos, este, amigos, ¿no? ¿Cómo fueron?

I: [...] en acá se burlaban mis amigos porque siempre hablaba un poco dif, no hablaba tan claro, tan, diferente, tan claro el castellano, oye serrano vaya pa' allá, me decían. Siempre me ha, yo me lloraba, señorita, me lloraba enorme: por qué, qué hablan, por qué tanto me desprecian acá, yo decía, si en allá nadie me decía nada, señorita; en allá en Huamanga nadie, nadie me insultaba, pero acá, señorita, me insultaban, serrano vaya pa' allá, habla bien, se escapa tu mote me -ecían. Trataba de no hablar pero siempre me salía. 
El contraste que Júver señala entre su pueblo y Lima permite establecer una correspondencia entre el tipo de espacio y el tipo de discriminación. El pueblo andino, de talla pequeña y con poca densidad y diversificación, constituye una esfera en la que la discriminación étnica y lingüística es casi nula. En cambio, Lima, de enorme talla y con alta densidad y diversificación, resulta una esfera especialmente sensible a las diferencias étnicas e idiomáticas para establecer distancias y segregaciones. En el caso de Júver, la discriminación lingüística que soporta está vinculada con una particular ideología y política del espacio. La sierra suele ser considerada un obstáculo para el progreso, un lugar arcaico, de barbarie y atraso, y en consecuencia, sus productos, su gente y sus lenguas son minusvalorados. Como contraparte de esa opinión ideológicamente orientada, la costa, lugar donde se encuentra Lima, aparece como el lugar de lo moderno y del progreso. Decirle a uno "serrano" actualiza esas connotaciones y sirve para establecer distancias y fronteras étnicas y culturales.

E: ¿Qué lenguas usas aquí en Lima?

I: El castellano.

E: [alguna] más ¿el quechua? ¿En qué momentos o circunstancias?

I: Lo uso quechua c-an- -toy con mi familia, c-an- -toy con mis abuelitas, c-ando vienen, con ellas, o si no mis tíos de Vitarte que están de mi mamá sus primos, con ellos hablamos en quechua, señorita.

E: Ah, ya. ¿Y vas a eventos culturales, de tus paisanos?

I: Sí, está por [avenida] Argentina, hay una fiesta que es de puro ayacuchanos.

E: $\mathrm{Mm}$

I: Fiesta ayacuchana, allá hay bastante, de todo, de todo sitio vienen: Comas, en Tablada viene ahí para reunir [quechua] nos hablamos o sea nosotros somos de allá sí en quechua hablamos, señorita, y es una alegría en allá conversar de eso de que acá así con mis amigos no puedo porque ellos hablan castellano nomás, ya se creen que son limeños. 


\section{E: ¿Y qué sientes cuando estás ahí con tus, este, paisanos hablando tu idioma?}

I: Me siento alegre, señorita, una alegría para mí.

En este segmento, Júver hace referencia a un tiempo y un lugar específico en el que se reproduce y celebra la pertenencia a una tradición lingüística y cultural andina particular, la de Ayacucho. Participar en esa esfera de afinidades, afectos y valores resulta gratificante para él ("es una alegría en allá conversar"), si bien se trata de un evento momentáneo que contrasta con la aspereza y dificultad comunicativa que experimenta en su nuevo hábitat ("con mis amigos no puedo [conversar] porque ellos hablan castellano nomás, ya se creen que son limeños"). Del mismo modo, Júver nos revela su experiencia de la inter-espacialidad: los ayacuchanos de diversos lugares de Lima se trasladan al lugar de la Av. Argentina para recrear ahí la fiesta que se celebra en Ayacucho. Un lugar reenvía a otros lugares; un lugar contiene otros lugares. Este caso sugiere que, para buena parte de los migrantes, Lima es vivida como una permanente construcción de redes que unen diversas áreas de la ciudad, y a ésta con otros territorios del país, principalmente de la sierra andina.

\subsection{Recursos lingüísticos}

Júver es bilingüe: domina el quechua ayacuchano y una modalidad andina emergente del castellano. Recurre al uso de una $u$ otra lengua, según los interlocutores, los momentos y los espacios. El quechua le sirve para establecer conexiones privilegiadas con la red de migrantes quechua-hablantes del sur andino peruano, sobre todo si estos son ayacuchanos; y el castellano, en tanto lengua vehicular, le es útil eventualmente para entrar en contacto con otros habitantes de la ciudad. Mientras el uso del quechua es esporádico y subordinado, el uso del castellano es frecuente y predominante. Ahora bien, el castellano de Júver es una modalidad de habla que discrepa de otras variedades habladas en la ciudad. Él mismo es consciente de tal diversidad y establece distinciones: la modalidad de los limeños que hablan "todo pituco, todo creídos" ${ }^{4}$ la modalidad de los que "se creen limeños" (monolingües nacidos en Lima, de padres migrantes), la modalidad de los que hablan como él (migrantes bilingües). Si se presta atención a los rasgos del español de Júver, se advierte que aparecen características tanto del "castellano andino" como

${ }^{4}$ A la pregunta: “¿Cómo crees que hablan los limeños?”, Júver responde: “Todo pituco, todo creídos hablan ellos, todo ellos hablan." 
del habla popular costeña. Entre los rasgos andinos, por ejemplo, aparece la doble marca del locativo (1a y 1b), la neutralización del género (2), el doble posesivo (3), el uso del loísmo (4), el uso de cita directa, seguida por la forma diciendo, para enlazar oraciones (5).

(1) (a) nadie hablaba el castellano en allá;

(b) si en allá nadie me decía nada, señorita.

(2) en la capital mismo.

(3) me caí del tercer piso de su casa de mi tía.

(4) tiqti lo dicen [a las alverjitas] por lo que son las alverjitas, eh, redonditas, por eso lo dicen tiqti. vámonos allá a surgir diciendo.

Entre los rasgos del habla popular costeña, tenemos el debilitamiento o la desaparición de la /d/ intervocálica (6a-6d), la aspiración o elisión de la /s/ en final de palabra (7), la supresión de consonante inicial (8) o de la sílaba final (9).

(a) hasta un día nos han bota-o de su casa;

(b) en allá nadie, nadie, te decía así, que tú has habla-o mal;

(c) un sitio -onde no hay lo que hay acá en Lima, ¿no?;

(d) serrano vaya pa' allá, habla bien, se escapa tu mote me -ecían.

pero ahí nomá- llegué a tener mi familia.

por los mismos problemas, mi -amá tenía miedo de mí.

no, yo $p a^{\prime}$ regresarme $p a^{\prime}$ allá.

El castellano de Júver es el castellano andino de su lugar de procedencia, pero "retocado", resocializado y transformado por sus nuevas interacciones en su proceso de inserción urbana, primero en Huamanga y luego en un asentamiento humano de Lima. Así, mientras mantiene algunos rasgos andinos, filtra otros, especialmente aquellos que resultan más directamente indicadores de la pertenencia a espacios rurales, como pudieran ser la inestabilidad en el uso de las vocales $e / i$ y $o / u,{ }^{5}$ el reacomodo acentual o la anulación de los diptongos. De esta manera, los rasgos del castellano de Júver remiten a sus rupturas y continuidades; a su biografía de desplazamientos espaciales y a las articulaciones que él experimenta y contribuye a recrear en su nuevo hábitat. Así, podríamos decir que su identidad

\footnotetext{
${ }^{5}$ Júver refiere que, al llegar a Lima, le resultaba difícil la pronunciación del castellano: "mi lengua no me soltaba para el castellano". Da a entender que ahora ya esa dificultad ha sido superada. De hecho, el rasgo más perceptible del castellano rural andino -la inestabilidad en la pronunciación de las vocales medias y altasprácticamente no existe en el discurso de Júver. Sólo una vez aparece la indistinción e/i: "me dicían agarra periódico".
} 
espacial e idiomática ya no es la de su pueblo en la serranía, ni la del citadino de Huamanga. Ahora, es urbana, más compleja y compuesta.

\section{El caso de Teófilo}

Teófilo tiene 30 años. Nació en Lima, pero a los tres años fue llevado a la sierra, a Chicmo (provincia de Andahuaylas, departamento de Apurímac), donde pasó su niñez y juventud, para luego volver a instalarse en Lima. Sus padres son de Chicmo y, al igual que él, tienen el quechua como lengua materna. Actualmente vive en la Asociación Niño Jesús, II etapa, en el Distrito de Ate. Al concluir su educación primaria y secundaria en Chicmo, Teófilo migra definitivamente a Lima y se ubica por un breve lapso en el Cerro San Cristóbal, en casa de sus primos. Sin embargo, el ambiente y las condiciones en que estos viven le impactan y le parecen peligrosas, así que decide irse a vivir con su prima en San Cosme. Allí permanece, al cuidado de ella, mientras trabaja y estudia mecánica de mantenimiento. Conoce a un amigo que lo invita a la iglesia adventista en donde conoce a su esposa. Una vez casado se muda a la casa que le regalan sus suegros, en el Distrito de Ate. Con el fin de prepararse para alcanzar la meta de tener su propio negocio, actualmente estudia administración de empresas en una universidad gestionada por los adventistas.

\subsection{Relato}

A través de su discurso, Teófilo toma una posición identitaria y elabora representaciones de sus espacios vividos y de los otros actores que aparecen en su campo migratorio. Consideremos este fragmento:

E: Bien... cuéntanos, ¿cómo te llamas?

I: Mm... mi nombre es Teófilo P. y... sería de nacimiento acá en Lima, ¿no? y natural de Apurímac, provincia de... Apurímac... departamento de Andahuaylas, distrito de Chicmo, sí.

[...]

E: Y dime, esto, ¿Tú te sientes más... tú te sientes limeño o te sientes provinciano?

I: $\mathrm{Mm}$, no me siento, más me siento peruano. Pero limeño... hay momentos que... me saca el, no, ah, me dicen eres limeño di-, a veces mi esposa me dice, ¿no? 
Oye, ¿tú eres limeño o provinciano?, ¿no? yo soy limeño de sangre, le digo, ¿no? porque saco este lado a veces por lo que he nacido acá y... me siento provinciano, por lo que a ve... porque he crecí-o en provincia.

$\mathrm{Al}$ indicar su lugar de origen, Teófilo no da una respuesta neta ni asertiva: recurre a la forma verbal sería, la cual evoca lo posible o no actualizado ("sería de nacimiento acá en Lima, ¿no? y natural de Apurímac"). Esta inseguridad se refuerza con la interrogación que busca una confirmación (“¿no?”). Ahora bien, esta formulación hipotética e inacabada sobre su origen e identidad da mayor énfasis a lo provinciano que a lo limeño, pues queda sugerido que, mientras su ser "natural" pertenece a Apurimac, Lima es sólo el lugar circunstancial de su nacimiento. Esta toma de posición identitaria frente a la entrevistadora no es, sin embargo, la única. El mismo entrevistado señala que "hay momentos" en que recurre a otra estrategia: dice ser limeño por naturaleza ("limeño de sangre") y tener sensibilidad por lo provinciano ("me siento provinciano"). En su primera toma de posición identitaria, Teófilo atribuye un mayor agenciamiento a su pertenencia provinciana; en la segunda, en cambio, a su pertenencia limeña. De ahí que rehúya el ser clasificado de un modo simple y cerrado, y que prefiera una categorización más amplia, la de ser peruano ("más me siento peruano"), que da cabida a la ambivalencia del mimetismo o camuflaje (Bhabha 2002: 150) y al ensamblaje dinámico de las pertenencias múltiples.

La Asociación, en la cual Teófilo tiene un cargo directivo, es el agente operador y transformador del espacio del barrio. Y el objetivo de esa organización es generar progreso para la comunidad y cada uno de sus miembros. Es por esto que, al ser preguntado por la posibilidad de cambiar de barrio, responde: "Mmm... no pienso, no pienso irme de mi barrio, más pienso, este, más pienso tratar de sobresalir y hacer diferente a mi barrio". Así, el deseo de quedarse en el barrio para una mejoría tanto personal (tratar de sobresalir) como comunitaria (hacer diferente a mi barrio) expresa un compromiso y una adhesión a un espacio, a un grupo humano diverso y al proyecto común de recrear un hábitat. Al interior del barrio, formado mayoritariamente por provincianos, se dan tensiones y rivalidades debido a que existen grupos que provienen de diferentes partes y se diferencian por sus costumbres:

Porque [aquí en el barrio] son más de provincia y a veces ahí se ve las diferencias, ¿no? a veces una mezcla de... de formas, de culturas se puede decir, ¿no? que no, no se entienden a veces entre ellos, se ve ahí están se 
juntan entre ar-quipeños, entre ayacuchanos y tiene sus costumbres que ellos, cada uno quieren dar sar... de... quieren sacar su cara, ¿no? pero... así pe en esto, ese es su situación de ellos, ¿no?

E: $Y$ entonces cuando celebran alguna... alguna fiesta, alguna actividad, no sé... esto, ¿se juntan todas las sangres?

I: Sí, todas... sí todos, pero... ah... a-eces inconscientemente la gente se ve que cada uno hace su grupito, ¿no? y ahí están hablando y quieren escuchar su música de su pueblos o algunos tratan de asimilar a otros que están la mayor cantidad y... tratan de incluirse, ¿no? los que son de la minoría, pero hay personas que son de mayor cantidad, por ejemplo los ayacuchanos quieren escuchar su música, quieren hacer su danza, presentar sus costumbres y algunos que son casi la misma cantidad de los eh... provincianos también quieren sacar su cara y otra competencia hacen, ¿no?

Otro factor diferenciador es el lingüístico. Teófilo señala que las lenguas maternas de los migrantes son sobre todo el aimara y el quechua. Al interior de esta última reconoce variantes de acuerdo con la procedencia geográfica de sus usuarios:

I: En... eh... lo que se escucha más... más es este... el quechua; y de Huancavelica también son quechuas.

E: $\mathrm{Mmm}$

I: De Cusco también son quechuas una parte, pero por Cusco y Puno ya también hablan aimará, ¿no? [...] el quechua de Apu... de Huancavelica, Ayacucho es algo similar, caso ¿no? no hay mucha diferencia; en cambio, el quechua ah... ah... quechua que es ayacuchano, ¿no? tam-ién se podría se puede decir el Apurimac, de Huancavelica y, a comparación con el quechua de Cusco, es muy diferente.

E: $\mathrm{Mmm}$

I: Sí, por -jemplo, se puede decir, ¿no? el agua... el agua le dicen... en Cusco unu, ¿no? y en Huancavelica le dicen yaku, ¿no? eh... y así hay diferencias, ¿no? por -jemplo este... en Cusco le dicen al frente... al frente le dicen 
jajayku, ¿no? y en... en quechua en Hua... Apurimac, Ayacucho, Huancavelica le dicen ayachima.

Más allá de estas diferenciaciones y controversias al interior de los migrantes, la magnitud y el peso de la presencia de los migrantes en Lima le parece a Teófilo algo decisivo, pues a sus ojos "la gente de Lima Lima" (la repetición aquí actúa como un marcador de identificación que tiene la connotación de "pura" o "propia") ha quedado prácticamente invisibilizada:

\begin{abstract}
Eh... se podría decir que Lima es una... población mayor parte lleno de provincianos, y saco mi conclusión de que la gente de Lima Lima, a veces eh no vive acá. A veces se van al extranjero o algunos se van a otros pai... ¿no? o algunos están por ahí, pero mayor parte, mayor parte lo que forma a Lima, lo que da vida, sentido es provincianos. Aunque puede ser ¿no? los padres vienen de provincia, sus hijos crecen acá y ellos viven acá, ¿no? y ellos los que están ahí ya. Y se ve más lleno de provincianos, ¿no? y los limeños también se están yendo a otro sitio.
\end{abstract}

El migrante de la primera mitad del siglo XX llegaba a una Lima habitada mayormente por limeños de larga tradición citadina y que ocupaban el centro de la ciudad. La Lima de Teófilo, en cambio, es una aglomeración urbana extensa, mayoritariamente compuesta por provincianos. Estos han rodeado la ciudad, borrándole los límites, y han ocupado buena parte del centro, haciendo salir de ahí a la élite que lo habitaba. El campo urbano limeño aparece así como una "espuma" constituida por innumerables "burbujas", aquellas en las que uno se mueve y encuentra gente conocida (los provincianos o los hijos de provincianos) y aquellas que configuran un horizonte desconocido e inimaginable.

No todos los limeños son iguales y no todos tienen la misma actitud ante los migrantes. Teófilo distingue tres tipos de limeños, según su procedencia y actitud frente a los provincianos: el "limeño puro", que discrimina, pero que cada vez se encuentra en menor número en Lima; el

\footnotetext{
${ }^{6}$ Las metáforas de la "espuma" y las "burbujas" son utilizadas y desarrolladas por Sloterdijk (2002 y 2005) para sustentar su concepción de la sociedad: "Par société, nous entendons un agrégat de microsphères de différents formats (couples, foyers, entreprises, associations) qui se jouxtent comme les bulles dans une montagne d'écume et se glissent par-dessus ou par-dessous les autres sans être, les unes pour les autres, ni véritablement atteignables ni effectivement séparables" (Sloterdijk 2005: 52). Esas metáforas son retomadas por Lussault (2007: 36-37, 84) para fundamentar su concepción del espacio humano, principalmente urbano.
} 
limeño que tiende la mano al provinciano haciéndole sentir que es parte de la vida y del sentido de Lima; el limeño que se siente limeño puro, pero que no lo es, pues sus padres son provincianos, y que discrimina y no valora al provinciano que habita en la ciudad, sirviendo de agente reproductor de una ideología racista. De hecho, la discriminación que él ha experimentado proviene de este último grupo:

\begin{abstract}
Sí... sí hay personas que... que son... que son provincianos que han naci-o acá en Lima y ya... se sienten un poco limeños puros y agraden, ¿no? a la gente, a ese serrano que no sirve -e nada, no, no eh, cuando... te podría decir, ¿no? A -eces este, este, eh... aquí había, ¿no? [...] cuando recién venía ¿no? y me decía ¿no? tú un día serrano qué vas a hacer con tu familia que... a tu esposa cómo vas a mantener, y en qué vas a trabajar, ¿acaso tú vas a... vas a mantener, pintando los dibujos vas a mantener a tu esposa? me sentí... pero triste [...] Por eso ese tipo son malos tipos racismo, ¿no? el que... los cholos allá, los... sí es un poco negro, justo, ¿no? un poco negrito que... no el tal negrito es así, ¿no?... a -eces ah... te marginan, te dicen que ¿no? tú no vales, ¿no? no te valora, ¿no? más ellos se valoran aunque se ve en su vida personal pésima que viven, ¿no? y... pero... a otros ni les... ni siquiera no valoran, ni siquiera a los [...] suegro, ni siquiera tendrán metas.
\end{abstract}

\title{
2.2. Recursos lingüísticos
}

Con el fin de responder a sus necesidades expresivas y comunicativas, los migrantes bilingües recurren tanto al castellano, lengua predominante del nuevo hábitat, como al quechua, lengua de su primera socialización. Teófilo hace referencia a los momentos y lugares en los que utiliza el quechua y a la manera en que esta lengua puede garantizar una plenitud en el intercambio entre paisanos:

E: Y aquí en Lima, ¿qué lenguas usas? ¿El castellano nada más o en algunas oportunidades el quechua también? I: Sí, porque, sí... hay... hay momentos en que hablo con...; por -jemplo, con mi suegro hablo quechua, ¿no? y a veces eh... los hermanos que son de la iglesia también hay algunos que... Ayacucho, de Huancavelica, $¿$ no? eh, cuando... en cada [...] conversar en quechua ya como que a... agarrarle quechua, ¿no? Ese es bien bonito hablar en quechua... más se entiende, es un... es una... 
es un i... es un idioma más eh... más detallado el amor, el sentimiento... quizá habla, se expresa algo parecido es todo ¿no? todo conforme.

Convencido de las ventajas de ser bilingüe, opta por iniciar en el quechua a quien no lo sabe, y lo hace de tal forma que se gana la admiración de los otros. Es decir, mientras que para otros el ser quechua-hablante podría ser un motivo de vergüenza que les llevara a tratar de ocultar su condición, para Teófilo esta circunstancia es una oportunidad de compartir y "ganarse" a los otros:

\begin{abstract}
No, a -eces eh... a veces yo le hablo, ¿no? acá... y algunos que no saben hablar quechua yo le hablo en quechua, ¿no? y me dicen ;ay, qué lindo!... a veces yo tenía que... tengo que ganarme, ¿no? a ellos para que lo siquiera hablen, ¿no? ¡hola!, ¿qué tal?, imaynallan, le digo ¿no? ‘¿cómo estás?' Y... ellos también ¡ay! ¿cómo has dicho? imaynallan, le digo, ¿no? y... ellos quieren aprender, jah, imaynallan! A veces ya otra forma ellos hablan, pero... así es... no te marginan. Pero hay algunos que no... no le caen bien, pero se cierran, ¿no? pero igual yo trato de compartirlo con lo que sé.
\end{abstract}

Podríamos decir, pues, que, además de utilizar el quechua para interactuar con otros migrantes bilingües del sur andino peruano, especialmente los procedentes de Apurímac, Huancavelica y Ayacucho, lo usa también como recurso de seducción intercultural, para invitar a los monolingües, a través del aprendizaje de algunas expresiones en quechua, a desear la lengua del otro, y en consecuencia, a abrirse a la diversidad cultural de la nación. En cuanto al castellano, esta lengua no sólo le sirve de instrumento comunicativo amplio, sino que también, al habérsela apropiado, se ha convertido para él en medio expresivo de las experiencias nuevas y originales al interior de su campo urbano-migrante. Puesto que su valoración del quechua es positiva, el influjo de esta lengua sobre el español también es positivo, imprimiéndole un "sabor" particular:

Por -jemplo los provincianos, provincianos a veces un poco... medio cantados hablamos, ¿no? cantando, medio cantando, y...y...por -jemplo de...de la selva ellos hablan poco, ¿no? hola, pe- cómo está, ¿no? y entonces hay una diferencia tanto, ¿no? En cambio, acá de Lima también ya un poco... serios, para... como para mí eh es un castellano sin sabor, así lo noto ¿no? 
Advertimos que, desde la perspectiva de Teófilo, la representación del castellano andino difiere notablemente de la opinión generalizada que lo considera un obstáculo para el progreso y el ascenso social. Pareciera, más bien, que Teófilo piensa el uso de la lengua como parte integrante de los recursos de democratización y de construcción de una sociedad inclusiva y de una nueva identidad nacional. En ese sentido, las variedades andinas del castellano constituyen recursos que, si bien irritan a muchos y producen discriminación y menosprecio, son aptos para canalizar las nuevas formas plurales y no excluyentes de organizar y vivir la ciudadanía. De otra parte, Teófilo sabe que existen distintas variedades de castellano, y también que las modalidades de habla de los migrantes tienen características que suelen ser utilizadas para marcar diferencias y distancias sociales. Uno de esos rasgos socio-indexicales ${ }^{7}$ es la inestabilidad en el uso de las vocales $e / i$ y $o / u$, muy presente en el castellano de la población rural andina. Los migrantes bilingües como Teófilo buscan superar esa insuficiente diferenciación en la pronunciación; y lo consiguen, aunque no siempre completamente. El siguiente fragmento ilustra esa dura adquisición de nuevos hábitos lingüísticos por parte del migrante bilingüe:

E: [...] un limeño que siempre ha hablado castellano y un limeño o una persona de provincia que sepa el quechua, ¿el castellano de los dos es igual o es diferente?

I: Mm... diferente, diferente. Hay una diferencia, ¿no? a veces lo que se viene de allá hay tiene una dificultad, ¿no? dificultad de hablar más claro. A veces dice... cuando yo primero recién estaba viniendo acá tenía mucho, ¿no? y... eh... por -jemplo cuando una palabra se -ice con i, se -ice con, se a -eces te escapa con $e$.

E: $\mathrm{Mm} \ldots$

I: $\mathrm{Y}$ a vece- eso es no... no es porque uno quiere, ¿no? a veces por la misma idioma que uno ha aprendido quechua se habla más [...]

Por este testimonio, uno podría pensar que Teófilo ya no debilita la distinción $i / e$ o $o / u$, sin embargo, como se puede observar en los ejemplos de (10 a-d), aún se le "escapan" algunas de esas indistinciones, aunque a veces las corrige inmediatamente. En

\footnotetext{
${ }^{7}$ Nos referimos a los rasgos socio-indexicales, en el sentido adoptado por Ploog \& Reich (2005: 50) como valores semánticos capaces de identificar hablantes y sus redes de interacción.
} 
todo caso, más allá de su grado de frecuencia, la inestabilidad en la pronunciación de tales vocales aparece como un rasgo que tiende a ser descartado del castellano de los migrantes andinos en el ámbito urbano limeño.

(10) (a) Por -jemplo, los provencianos, provincianos a veces un poco... medio cantados hablamos, ¿no?

(b) paricen, parecen pero es en el sonido, este... pero son diferentes.

(c) no tenía esa idea de que mis primos vevían en un solo cuarto diez amigos, quince amigos, ¿no?

(d) y hay personas tam-ién que se confurman con lo que tienen, ¿no?

Otros de los rasgos andinos del castellano de Teófilo son el doble posesivo (11), la discordancia de género (12 y 13), la discordancia de número (14 y 15), el loísmo (16), el calco gramatical del locativo quechua chaypi 'ahí': chay 'eso' + pi 'en' (17 y 18).

(11) y ahí están hablando o quieren escuchar su música de su pueblo

(12) más lo veo a la gente, eh, ¿no? lado bueno tiene, hay personas que tienen esas deseos de... hacer algo por la vida.

(13) Pregunta: te voy a pedir que me leas esta lista de palabras/ Respuesta: te lo leo.

(14) a veces los varones le cantábamos a las mujeres, ¿no?

(15) las mujeres también nos correspondía.

(16) a veces los varones, los varones lo cantamos a las damas.

(17) me hice amigo con ellos, ¿no? ya entré a la iglesia, en eso me conocí a... a mi esposa que es Paulina, ¿no?

(18) ni aún en mi pueblo no había propio... profesionales de con quienes yo podía conversar y... en eso... bien fracasado me sentía.

Pero al lado de estos rasgos, se encuentran también otros que corresponden al castellano de la costa, como, por ejemplo, el debilitamiento o desaparición de la /d/ intervocálica (19), o la aspiración o elisión de /s/ en final de palabra (20).

(19) Vine acá a Lima y he trabaja-o en el mercado mayorista.

(20) y entonce- lo veo ahí. 


\section{El caso de Esther}

Esther tiene 51 años. Nació en Villa de Arma (Provincia de Castrovirreyna, Departamento de Huancavelica). Sus padres nacieron en el mismo lugar y tienen, al igual que ella, el quechua como lengua materna. Actualmente vive en el asentamiento humano Amauta, en el Distrito de Ate (Lima). Cuando tenía cinco años, dejó la sierra y se mudó a vivir con sus abuelos a la ciudad costeña de Chincha. Allí hizo sus estudios primarios y permaneció hasta cumplir los trece años. En ese momento sus tíos y abuelos deciden que debe ir a trabajar a Lima como empleada doméstica y la entregan al cuidado de una señora limeña. Luego de un tiempo, Esther misma decide volver a Chincha, a la casa de sus abuelos. A los quince días de haber retornado, su tío dispone que ella vuelva a trabajar a Lima. Es así como la lleva a buscar empleo en el Jirón Paruro, en el centro de la ciudad, y la entrega a una familia de origen japonés. Ahí trabaja en todos los oficios domésticos, pero sus nuevos patrones incumplen la promesa de darle el tiempo y el dinero necesario para que estudie corte y confección. Después de un año, cambia de empleo, esta vez en un lugar de mayor prestigio. En efecto, va a Surquillo, un distrito de mayor estatus, donde una señora que trabaja en modistería y que le permite estudiar corte y confección en horas de la tarde, así como ayudarle en su trabajo de costura. Pasados tres años, y al obtener su certificado del Ministerio de la Educación, Esther decide volver a la provincia a buscar a su madre. Desea mostrarle sus logros. A su vuelta a Chincha, conoce al padre de su primera hija y se queda a vivir allí por 17 años. Después de este lapso, la familia vuelve definitivamente a Lima, se instala en una habitación alquilada y a los tres años consigue su propio terreno en el asentamiento humano Amauta, en el Distrito de Ate.

\subsection{Relato}

Esther relata su primer viaje de Chincha a Lima. Era una niña y otros deciden por ella. Siente que la enviaron a la capital como si fuera un paquete o "encomienda":

Entonce- la señora dijo ya que li... -liste su ropitas todo... y ya mañana en el primer carro las ocho -e la mañana lo voy a embarcar y ya que se vaya, ya y... yo le voy a llamar por teléfono a mi hija... que lo reciba allá... que le espere en casa. Y verdad al día siguiente -listé mis ropitas y me... me fui y la señora me embarcó en el carro pe- y po- eso digo yo que me han manda-o prácticamente como una encomienda y al chofer dice... 
señor Canales [...] me lo dejas a la se... a la chica este... a mi hija en tal dirección tal ahí [...] y toqué la puerta y la señora salió pe- y el señor dijo: señora, tu mamá me mandó a la chica y ahí -ta la chica y ahí -ta sus bultos; ya prácticamente como una encomienda, ¿sí o no?... ese es mi recuerdo mío.

Relata también sus experiencias con cada una de sus tres patronas. La primera de ellas es una profesora:

Pasa adelante, me dice, acá vas a trabajar conmigo que... cuántos años tienes, yo tengo trece años, ya este... me dice yo tengo un niño, vas a cuidar al niño, yo todas las mañanas me salgo a trabajar al colegio y estoy viniendo a la una a almorzar ya a las doce a la una me dice y ya yo te vo- a enseñar a cocinar. [...] lo que más me dolía siempre todas las mañanas es que la señora me servía una tacita -e cuáquer una tacita plástica... cuáquer con una cucharadita chiquita de azúcar no más y un pancito con mantequilla, me decía ya Esther toma tu desayuno y para mí era bien doliente porque en sí yo en mi casa... mi abuelito me había cre...criado todo pobre pero comíamos bien, para qué, mi agüelito sí... de niña me enseñó a trabajar en el negocio... yo trabajé y llevábamos la plata y mi abuelito nos hacía comer muy bien...

Para Esther, comer suficientemente no es cuestión de ser o no pobre, sino cuestión de hábitos, de costumbre, de respeto, de dignidad. La informante no juzga esta diferencia, por ejemplo, calificando a su patrona limeña de tacaña o avara. La recreación de la escena está más bien centrada en la sorpresa y en el impacto que para ella fue resignarse a recibir tan poca comida. Su segunda patrona fue una limeña de origen japonés. Aunque le pagaba muy poco salario y el dinero no le alcanzaba para pagarse los estudios en la academia, guarda un buen recuerdo de ella:

Era buena, me trataba como a su hija po-que todos sus hijos eran hombres y... en eso, la señora cuando salía nunca me dejaba en su casa sola, por donde ella se iba, me llevaba. Tenía compromiso me llevaba, junto comía, a de cuenta, me vestía bien... me compraba mi ropa con mi plata que ganaba... esa ropa te queda bonito, te vas a vestir con esto. Mi zapato, todo me compraba ella misma. Ella me vestía y me llevaba pa- donde ella iba 
los paseos así, todo sitio me llevaba, nunca me dejó. Y así... la señora me crió así...

Su tercera patrona fue una modista de San Antonio, en Surquillo. La trataba con respeto y afecto, no la recargaba de trabajo y le dio la oportunidad de empezar y terminar sus estudios de corte y confección:

\begin{abstract}
Esthersuca me -ecía, Esthersuca lava tus servicios rápido, -lístate ya pa que te vayas me -ecía y solamente la señora me tomó pa- limpieza, en la hora del almuerzo pa- ayudar a lavar los servicios [...] Y el resto del día yo me dedicaba a ayudar a coser la señora. En sí, la verdad, la señora me ha enseñado. Ya... ella hacía vestidos de alta costura. Antes usaban ese vestidos largos... con forros, con lentejuelas... ese era... la señora trabajaba entonces me decía Esther me tienes que empal... empalmar aprender a empalmar forros así, así... ya me iba... me -ice encandelilla acá... las orillas ya todo me... me enseñaba... [...] y ahora la señora me -ice sabes qué Esther me dice, junta tu platita lo que te estoy pagando, no te estés gastando todo, si no yo lo guardo... y mi hermana está yendo a los Estados Unidos de ahí que te traiga esa máquina mira esta máquina es que tú ya sabes dominar esta máquina me decía porque tenía su máquina que remallaba y que cosía recta. Mira tú con... esa máquina era... un palito que bajaba y tú machucabas con tu pierna lo... este... y cosía todo esa máquina [...] todas maneras tienes que comprar tu máquina Esther me dice para que tengas más práctica ahí en tu cuarto bonito lo armas.
\end{abstract}

Bajo la tutela de esta última mujer limeña, Esther logra sus objetivos de obtener un certificado en corte y confección avalado por el Ministerio de Educación, practicar lo estudiado en el negocio de la patrona y adquirir su propia herramienta de trabajo. Si se pensara la historia de vida de la informante como una suerte de "viaje del héroe", en el sentido de Propp (1985: 69-72), se podría decir que este tercer ciclo representa la apoteosis de la heroína, la culminación de los propósitos que la instaron a la partida inicial y que ahora le permiten pensar en el retorno triunfal, que es lo que, en efecto, Esther hizo en su vida real. Luego de 17 años de permanencia en Chincha, donde se casa y trabaja en su oficio, regresa definitivamente a Lima. Este retorno a la ciudad en la que ya había vivido es como un nuevo descubrimiento de la ciudad y de sus habitantes. Es más, para 
Esther ese nuevo contacto es el verdadero conocimiento de Lima. Al ser interrogada por la entrevistadora acerca de las diferencias que había percibido en Lima entre estos dos periodos, ella responde que no sabría informar de los cambios de esta ciudad, porque sus primeras permanencias en Lima se caracterizaron por el encierro. Sin embargo, Esther reconoce en sus primeros trayectos a Lima, así como en su estancia en Chincha, el punto de partida de una transformación a la que se refiere como "acriollamiento":

Porque en sí, en sí yo serranita, serranita no he veni-o porque yo he sido criada en Chincha [...] a los trece... a los trece años ya había dado un cambio pue- no era serranita, serranita. Ese... una cosa muy distinta cuando recién directo vienen de la sierra a Lima pe; en cambio, yo no... ya no era eso ya [...] Entonce- ya la persona que te ve ya no te ven serranita serranita... ya lo ve cambiado, sí. Porque en sí ya yo tenía viviendo ya en Chincha cuántos años. Sí, ajá, ya estuve -criollándome ya más, claro.

Su condición de no ser "serranita, serranita" le permite una mejor inserción y adaptación a la ciudad, pues, según su perspectiva, las personas que vienen directamente de la sierra a Lima suelen ser más tímidas, mientras que aquellas que ya se han "criollizado" se sienten menos cohibidas, y por ello suelen ser menos objeto de burla por parte de los limeños. Por otro lado, Esther tiene la certeza de que para los limeños los grupos migrantes son un obstáculo y causantes de problemas en la ciudad:

La gente de Lima siempre... nos trata de que... por qué venimos tanto a Lima los provincianos, por qué no se quedan en su tierra, deben quedarse en su tierra, deben quedarse en su tierra, solamente vienen acá a sufrir, a lamentarse que viven mal, dicen ¿no? [...] y siempre las personas dicen por qué esta gente habrán venido acá dicen ellos, ¿no? por qué habrán veni-o acá, a obstacular hacer obtáculo prácticamente pa- los gente limeño tam-ien somos obstáculos, -tamos obstaculizando dice, porque siempre he escucha-o eso.

Pero la verdad es... que yo digo no puede ser un obstáculo, ¿no? porque... si hay una opción donde que tú tienes un trabajo no estás obstaculizando. Obstáculo sería siempre en cuando tú le estés quitando algo $a$ ellos. Por ejemplo, si ellos tienen su trabajo o tienen su 
profesión y tú también tienes un trabajo, mientras tú tienes un lugar dónde trabajar creo que no estás obst... obstaculizando a ellos.

Para Esther, los provincianos que vienen a la ciudad no viven "mal", como dicen los citadinos, ni son un obstáculo para nadie, sino que encuentran un espacio propio. Particularmente, ella ya tiene su terreno en Amauta. Pero es interesante advertir que, sólo en este punto de la entrevista, Esther toma una actitud inusual: por medio del pronombre ellos, se refiere a los limeños como aquellos pertenecientes a un grupo diferente y generaliza su apreciación. A lo largo de la entrevista, Esther evita a toda costa esta actitud. Por esto es elocuente que en el tema sobre el ser o no ser obstáculo, se evidencie por única vez este deseo de diferenciarse y generalizar, el cual podemos interpretar como la parte de la representación social de los limeños que cobra más fuerza para la informante. ${ }^{8}$ Esa indicación del discurso de Esther nos revela, pues, lo sensible y relevante que resulta la disputa de espacios y de representaciones. En efecto, se actualiza y se enfrenta el prejuicio difundido entre gran parte de los limeños, según el cual los provincianos impiden el mantenimiento óptimo de los espacios y de la calidad de vida, paralizan la mejora de los barrios o los distritos a los que llegan y son los causantes del deterioro, a tal punto que su presencia obliga a los limeños a cambiar de espacio, a huir de los "invasores".

\subsection{Recursos lingüísticos}

Al igual que Teófilo, Esther tiene una visión positiva de su lengua materna. Ve las ventajas de su bilingüismo e intenta que sus hijos, aunque menos expuestos al quechua, puedan adquirir alguna competencia en esa lengua:

E: Su primera lengua fue el quechua.

I: Quechua y mi segunda es castellano, sí. Ya a mis hijos tam-ién... mi Carola entiende pero no habla, el Beto, ellos tam-ién que ahí siempre me siguen lo que yo hablo.

\footnotetext{
${ }^{8}$ En contraste, y corroborando lo anteriormente expresado, vemos que, más adelante en la entrevista, Esther es interrogada sobre otras actitudes de los limeños frente a los provincianos, a lo cual ella responde, evitando la generalización: E: Y esas personas que son limeñas eh... ¿qué opinión tienen del quechua, del aymara o de las lenguas andinas, las lenguas de la sierra? ¿Cree usted que le dan el mismo valor que le dan al castellano o al inglés? / I: Mm... algunas personas sí he escucha-o que sí, pero algunas que no. Algunas no lo valoran, alguno sí... depende de la conciencia de cada persona.
} 
Porque, ¿sabes por qué yo no me he olvidado? porque mi agüelita todo el tiempo me hablaba en quechua y yo respondía en castellano y ya ahorita que soy adulta me gusta, no me gusta olvidar porque hay muchas provincianas que vienen un año, dos años, cinco años, ya no saben hablar, pero sin embargo a mí siempre me ha gusta-o cultivarlo no me ha gusta-o olvidarlo ¿por qué? porque para mí es un orgullo.

E: Claro.

I: Aja.

E: Y le enseña también a sus hijos.

I: Y tam-ién de paso le voy hablando, enseñando a ellos y entonce- de repente ellos también... si les gusta algún día de -pente llegan a aprender, ¿no?

E: Claro.

I: Ajá.

En lo que concierne al castellano, Esther sabe que existen rasgos que indican que uno procede de la zona rural andina (la sierra). Estos rasgos se van filtrando a medida que uno se va "acriollando", si bien muchas veces algunos de ellos resultan persistentes:

E: Y usted, ¿ha notado alguna diferencia o puede ver una diferencia entre el castellano que hablan los limeños limeños y el castellano que hablan los provincianos? $[\ldots]$

I: Sí, hay, porque a veces yo mismo me... me equivoco, ¿no? porque... imagínate tú por decir que dices este... como te puedo decir... una palabra... comunicación y de repente hay personas que no lo pronuncian claramente y entonces ahí se distingue, ¿no? de repente la $i$ puede ser con la $e$ ¿no? entonce- ya tú ya directamente ya -tas ah... calificando que esa persona es de la sierra, ¿no? siempre te... algunas letras o sílabas lo pronuncias con mayor fuerza o con menor fuerza, entonce- ahí donde que uno se da cuenta, ¿no? 
E: Claro. Y... y entonces, ¿podríamos decir que es un castellano mal hablado?

I: O sea que -ta cometiendo como un barbarismo, ¿no? como un barbarismo o... esa persona t-avía le falta prácticamente practicarse en el castellano, por eso que lo pronuncia así porque no creo que sea malo tampoco, porque simplemente -ta errando en no hablar claro, ¿no es cierto? porque le falta la práctica, ¿no?

Un aspecto por subrayar es que Esther no considera "malo" el hecho de que se dé un influjo del quechua sobre el castellano, sino que lo sitúa en el ámbito de la práctica y el aprendizaje. Para ella, no se trata de evaluar negativamente o de descalificar moralmente las variedades andinas del castellano, sino de entender la diversidad de las prácticas idiomáticas, sociales y culturales. Si consideramos ahora el castellano de Esther, encontraremos los siguientes rasgos del castellano andino: inestabilidad en la pronunciación de las vocales i/e (21a - d) y o/u (22 a y b); la doble marca de posesivo (23 a-c), la discordancia de género (24) y número (25); el pluscuamperfecto del indicativo para referirse a acciones no experimentadas y a acciones que se acaban de descubrir (26).

(21) (a) yo ricién llegué a valorar mi madre [...] ese día recién valoré a mi madre.

(b) yo oraba siñorcito, Dios mío ayúdame sacar de acá porque acá yo no estoy bien, le decía.

(c) siempre venía a peropear, siempre me buscaba así.

(d) yo algún día tenía que trabajar endependiente.

(22) (a) ya no alcanzó la matrícola en la secundaria... me llevó a la academia, no, en la academia me matriculó.

(b) 0 sea no está en cunclusión todos pe.

(23) (a) no sé cómo se llamaba su... su allegados de ellos.

(b) la señora -ecía y así yo cumplía sus órdenes de la señora.

(c) creo que se llamaba... me he olvida-o su nombre de ella.

(24) (a) el único salida que yo he pensado es que... mejor te vas a ir Lima.

(b) tampoco no es bueno que ustedes le den mucho rienda suelto. 
(c) mi mamá, ya muchos años no lo veo a mi mamá, me dice ya anda véalo, visítalo a tu mamá.

(25) dicen ellos, ¿no? por qué habrán veni-o acá, a obstacular hacer obstáculo prácticamente palos gente limeño.

(26) dije que... ese era casado y me estaba engañando ves, decía yo pue- no. Con la tía... tía Julia era muchacha pue- yo dije había teni-o su señora y sus hijos, para eso era Miki y este... Marina y creo que ya había Sara bebita creo ya. Ay, este hombre ya tenía dos, tres hijos ya, qué malo, bien me decían mis tíos que los hombres son engañosos.

Junto a los rasgos andinos mencionados, aparecen también características del castellano costeño como el yeísmo o la elisión de $/ \lambda /$ (27), la elisión de la /d/ intervocálica (28), la aspiración o eliminación de /s/ en posición implosiva (29), o la velarización de la oclusiva labial en posición implosiva (30).

(27) yo soy de Vi-a de Arma.

(28) yo me he cria-o allá [...] y de ahí ya me he veni-o a Chincha, en Chincha me han trai-o mis abuelitos, en Chincha me han criado ahí. En Chincha he estudia-o mi primaria, ya y... de ahí a los... terminé mi primaria a los trece años... trece años me he veni-o acá a Lima.

(29) (a) con ese vestido largo nomá- porque ella la señora misma me ayudó.

(b) entonce- ahí donde que uno se da cuenta, ¿no?

(30) pedir a la empresa que nos dé occión.

\section{Conclusiones}

A través de sus relatos, cada uno de los entrevistados ha descrito su campo urbano- migratorio. Así, hemos podido conocer que, antes de la llegada definitiva a Lima, cada uno tuvo desplazamientos preparatorios: entre Pomabamba y Huamanga (Júver), entre Lima y Chicmo (Teófilo) o entre Villa de Arma y Chincha (Esther), durante los cuales se fueron dando procesos de iniciación lingüística (adquisición del castellano) y cultural (acriollamiento). Ahora en Lima, los tres comparten la misma área urbana (Distrito de Ate, en el Cono Este de Lima), cada uno dentro de una esfera comunitaria particular denominada "asociación" o "asentamiento humano", al interior de la cual se tejen relaciones (entre amigos, paisanos y vecinos) y se crean institucionalidades (asociaciones, comités y 
clubes); y, a partir de esta esfera se construyen espacios personales (individualidades) y se establecen conexiones inter-espaciales, con otras áreas y lugares de Lima (otros barrios, el lugar de la fiesta regional o de celebración religiosa, los lugares de trabajo o estudio) o del territorio nacional (Ayacucho, Apurimac y Huancavelica). En tanto actores de un nuevo hábitat, experimentan confrontaciones internas (entre migrantes de distinta procedencia, entre migrantes y los limeños de primera generación) y externas (los limeños de otras áreas urbanas, los "limeños limeños"). La multiplicidad de sus interacciones y de los vínculos que establecen agudiza la tensión "entre la diversidad de roles y la unidad de la persona" (Grafmeyer \& Authier, 2008: 21), tensión que se resuelve en una reelaboración dinámica de sus identidades y en la cual, al mismo tiempo, se oponen $\mathrm{y}$ articulan sus pertenencias andinas y conurbanas.

Al examinar los recursos lingüísticos de los entrevistados, se advierte que el quechua no ha dejado de ser utilizado en Lima, si bien su uso se circunscribe a espacios y momentos específicos. De otra parte, se constata que el castellano de estos tres migrantes andinos bilingües constituye una modalidad emergente caracterizada tanto por rasgos del castellano andino como por rasgos del castellano de la costa. En efecto, mientras algunos rasgos andinos, como la inestabilidad vocálica, tienden a ser eliminados, otros persisten, como es el caso de la doble marca del posesivo, la neutralización del género y número, o algunos calcos gramaticales. Junto a este proceso, se da la adhesión a elementos del habla costeña, en particular a aquellos que resultan emblemáticos, como el debilitamiento o supresión de /d/ en posición intervocálica, o la aspiración o elisión de /s/ en posición final de palabra. Este conjunto lingüístico híbrido emergente se perfila, al menos al interior de uno de los conos de la ciudad, como un instrumento idóneo para expresar nuevas sensibilidades y experiencias, así como para hacer posible la introducción de nuevos actores en la organización ciudadana limeña.

\section{Bibliografía}

Bhabha, Homi. [1994] (2002). El lugar de la cultura. Buenos Aires: Manantial. Grafmeyer, Yves \& Authier, Jean-Yves. (2008). Sociologie urbaine. Paris: Armand Colin.

Lefebvre, Henri. (1972). La ville et l'urbain. Espace et Politique. Paris: Anthropos.

Lévy, Jacques \& Lussault, Michel. (2003). Dictionnaire de la géographie et de l'espace des sociétés. Paris: Éditions Belin.

Lussault, Michel. (2007). L'homme spatial. La construction sociale de l'espace humain. Paris: Éditions du Seuil. 
Mongin, Olivier. (2005). La condition urbaine. La ville à l'heure de la mondialisation. Paris: Éditions du Seuil.

Plogg, Katjia \& Reich, Ulli. (2005). “Rasgos socio-indexicales en la dinámica urbana”, Lexis, vol. XXIX, no 1, pp. 47-78.

Proyecto Local. Nuevos Yacimientos de Empleo en Huaycán: http://www. proyectolocal.org/DetalleProyecto.asp?IdProyecto=1. (Página web de la Organización No Gubernamental "Proyecto Local"). [Consultado el martes 11 de abril de 2006].

Sartingen, Kathrin \& Gugenberger, Eva. (Eds.) (2011), Hybridität Transkulturalität - Kreolisierung. Innovation und Wandel in Kultur, Sprache und Literatur Lateinamerikas. Viena: Lit Verlag.

Sloterdijk, Peter. (2002). Bulles. Sphères I. Paris: Pauvert. . (2005). Écumes. Sphères III. Paris: Maren Sell Éditeurs. 
